\title{
Complications of intraoperative epidural steroid use in lumbar discectomy: a systematic review and meta-analysis
}

\author{
Oluwaseun O. Akinduro, BS, ${ }^{1}$ Brandon A. Miller, MD, PhD, ${ }^{2}$ Diogo C. Haussen, MD, ${ }^{3}$ \\ Gustavo Pradilla, MD, ${ }^{2}$ and Faiz U. Ahmad, MD² \\ ${ }^{1}$ Morehouse School of Medicine; and Departments of ${ }^{2}$ Neurological Surgery and ${ }^{3}$ Neurology, Emory University School of \\ Medicine, Atlanta, Georgia
}

\begin{abstract}
OBJECT The authors' aim in this paper was to review the intraoperative use of epidural steroids in lumbar discectomy surgery with a focus on surgical complications.

METHODS A comprehensive literature search was done using PubMed, MEDLINE, and the Cochrane Central Registry of Controlled Trials. Relevant papers were retrieved and analyzed. The authors performed a meta-analysis of all available data. Search terms included epidural, steroids, discectomy, lumbar disc surgery, herniated lumbar disc, methylprednisolone, and perioperative.The primary outcome was surgical complications such as wound infection or need for reoperation. Secondary outcomes were pain and postoperative narcotic usage.
\end{abstract}

RESULTS Sixteen trials and 1 retrospective study (a total of 1933 patients) were eligible for inclusion in this study. In all studies, steroids were added epidurally over the nerve root before closure in cases, and control patients underwent discectomy alone. The mean age (42.7 years vs 42.4 years; $\mathrm{RR} 0.30$ [ $95 \% \mathrm{Cl}-0.30$ to 0.90$], \mathrm{p}=0.32$ ), overall complication rates $(2.69 \%$ vs $1.18 \%$; RR 1.94 [95\% $\mathrm{Cl} 0.72-5.26], \mathrm{p}=0.19)$, and infectious complication rates $(0.94 \%$ vs $0.08 \%$; RR 4.58 [ $95 \% \mathrm{Cl} 0.75-27.95], \mathrm{p}=0.10$ ) were similar between the steroid group and control group, respectively.

CONCLUSIONS There is good evidence that epidural steroids can decrease pain in the short term and decrease the usage of postoperative narcotics after lumbar spinal surgery for degenerative spinal disease. The authors' results demonstrate a trend toward increased infection with epidural steroid use, but there was not a statistically significant difference. More studies are needed to validate the long-term risk/benefit ratio of epidural steroids in lumbar discectomy. http://thejns.org/doi/abs/10.3171/2015.7.FOCUS15269

KEY WORDS epidural steroids; lumbar discectomy; complications

$\mathrm{L}$ UMBAR disc herniation can lead to debilitating pain and discomfort. The surgical treatment of choice sis is lumbar discectomy. Approximately 2 of every 1000 Medicare patients will undergo lumbar laminectomy with or without discectomy. ${ }^{35}$ Even after discectomy, some patients continue to experience radicular pain. Many surgeons administer epidural steroids intraoperatively over the exposed dura and/or nerve root after discectomy to decrease postoperative pain. There is considerable variability among surgeons in the use of intraoperative epidural steroids. In a Canadian study published in $2009,49 \%$ of surgeons routinely used epidural steroids after surgery. ${ }^{6}$ With this widespread but nonstandardized use of epidural steroids after lumbar discectomy, a better understanding of their associated risk is warranted.

Recently, 2 consecutive patients in our practice underwent an uncomplicated lumbar microdiscectomy and received $40 \mathrm{mg}$ of triamcinolone acetonide epidurally on the nerve root. Both patients returned to the hospital with a symptomatic CSF leak within 2 weeks of surgery and needed revision surgery. In both of these cases, the CSF leak site was posteriorly on the dura/root (where the bulk of the steroid was placed) and was easily repaired. Considering that these leaks would have easily been seen intraoperatively, we contemplated whether steroids had any role in their creation. This experience prompted us to undertake this study. 
There have been 2 reviews addressing the use of epidural steroids after lumbar discectomy and both focused on functional outcomes such as pain reduction and postoperative hospital stay. ${ }^{16,31}$ Neither directly addressed surgical complications. In 2010, Ranguis et al. published a systematic review of 12 trials published between 1992 and 2008 that examined whether epidural steroid usage after lumbar discectomy led to a decrease in postoperative pain. ${ }^{31}$ In 2014, Jamjoom and Jamjoom published a review that added trials published between 2009 and $2012 .{ }^{16}$ Since 2012 there has been 1 additional prospective randomized trial discussing epidural steroid use. ${ }^{2}$ None of these reviews examined complications associated with epidural steroid use in a systematic fashion. This study analyzes all available data on complications associated with epidural steroid use. Complications addressed included infection, arachnoiditis, reherniation, durotomy, and CSF leak.

\section{Methods \\ Literature Search}

A systematic search of the PubMed, MEDLINE, and the Cochrane Central Registry of Controlled Trials databases was done following the guidelines outlines in the Preferred Reporting Items for Systematic Reviews and Meta-Analyses (PRISMA). The search was done using different combinations of the following terms: epidural, steroids, discectomy, lumbar disc surgery, herniated lumbar disc, methylprednisolone, and perioperative. The full texts of the appropriate studies were retrieved and analyzed by 2 authors. The date of the last search for this review was December 4, 2014. Duplicates were eliminated, and the remaining titles/abstracts were screened.

\section{Eligibility Criteria}

To be included in our analysis, the articles had to be randomized controlled trials, cohort studies, or retrospective studies of patients who underwent lumbar discectomy and had steroids applied onto the exposed nerve root or dura during the operation. Excluded from this analysis were articles in which patients had steroids administered intravenously ${ }^{3,20,21}$ or intramuscularly. ${ }^{10}$ Also excluded were studies in which the patients were treated with epidural nonsteroidal analgesics. ${ }^{26,34}$ However, we did include trials in which a combination of steroids and local anesthetics was used, as the focus of our review was complications from epidural steroids. ${ }^{5,9,15,17,28}$ We did not include trials in which the full text was not available ${ }^{14,23,27,30}$ or those not written in the English language. ${ }^{4,19}$

\section{Primary Outcome}

The primary outcome for this study was surgical complications. This includes reherniation, hematoma formation, CSF leak, infection, repeat surgery, persistent radicular pain or new neurological deficit, and arachnoiditis. Secondary analysis for infectious complications was performed. Systemic complications such as abdominal distention, urinary retention, or pulmonary embolism were not analyzed.

\section{Statistical Analysis}

Continuous variables are reported as mean \pm SD. Categorical variables are reported as proportions. Dichotomous outcomes were analyzed using the number of events in each group and the total number of participants to calculate the risk ratio. For continuous variables, the means and SDs from each study were used to calculate the mean difference. A random-effects model was used; 95\% confidence intervals were calculated. Statistical analyses were performed using Review Manager (RevMan version 5.3, Copenhagen: The Nordic Cochrane Centre, The Cochrane Collaboration, 2014); $\mathrm{p}$ values $<0.05$ were considered statistically significant.

\section{Results}

Sixteen trials and 1 retrospective study fit the criteria for inclusion as outlined in the PRISMA flow diagram in Fig. 1. All 17 of these studies included patients who had undergone lumbar discectomy. This analysis included a total of 1933 patients, with 742 patients who received steroids and 1191 patients who did not receive steroids (Table 1). The dosage and type of steroid used varied between studies. The steroids used were methylprednisolone acetate $80 \mathrm{mg},,^{2,7-9,15,25}$ methylprednisolone $40 \mathrm{mg},{ }^{1,22,24,28,29,32}$ methylprednisolone sodium succinate $80 \mathrm{mg},{ }^{12,17}$ dexamethasone, ${ }^{11}$ hydrocortisone, ${ }^{18}$ and triamcinolone aceton$\operatorname{ide}^{5}$ (Table 1). The average age, number of patients, type of steroid used, assessment method for pain, and overall complications for each study are summarized in Table 1. The mean age was similar between the 2 groups ( 42.7 vs 42.4 years; RR 0.30 [95\% CI -0.30 to 0.90 ], $\mathrm{p}=0.32$ ).

Analyses of risk ratios and 95\% CI with forest plots of the overall and infectious complications occurring in the included studies are displayed in Figs. 2 and 3. The overall complication rates (2.69\% vs $1.18 \%$; RR 1.94 [95\% CI 0.72-5.26], $\mathrm{p}=0.19$ ) and infectious complication rates ( $0.94 \%$ vs $0.08 \%$; RR 4.58 [95\% CI 0.75-27.95], $\mathrm{p}=0.10)$ were similar between the steroid group and the control group, respectively.

Analysis of studies reporting significant and nonsignificant reduction in the consumption of postoperative narcotics, postoperative hospital stay, pain reduction, and reduction in use of narcotics is summarized in Table 2. Five of the 7 studies that reported on changes in neurological status found a significant improvement after use of steroids. Seven of the 14 studies found a reduction in hospital stay with use of steroids. Similarly, most of the studies reported pain reduction (8 of 12) and reduction in narcotics use (10 of 11 studies) after use of steroids (Table 2). There were 5 reported cases of CSF leak in 2 studies, ${ }^{7,17} 3$ in the steroid group and 2 in the control group. These did not reach statistical significance due to small numbers $(p>0.05)$.

\section{Discussion}

Many patients will continue to have back and leg pain following lumbar discectomy. This has been attributed to several causes, including insufficient discectomy, insufficient rehabilitation, incorrect diagnosis, or complications such as recurrent disc herniation, arachnoiditis, epidural 


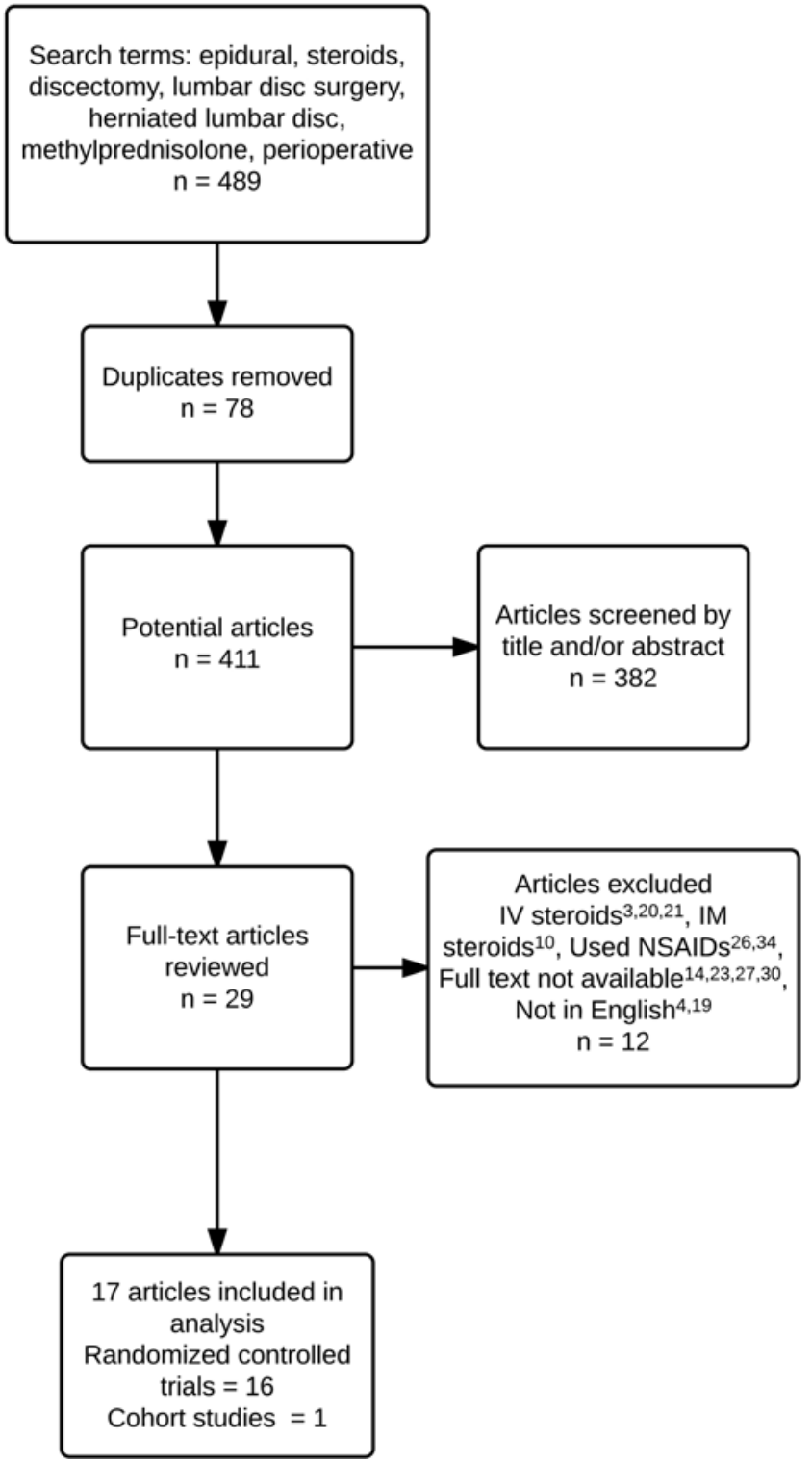

FIG. 1. Flow diagram illustrating systematic review of published literature evaluating epidural steroid usage in lumbar discectomy. IM = intramuscular; IV = intravenous.

fibrosis, or infection. Epidural steroids are often used as an adjunct to improve preoperative pain or reduce acute postoperative pain. Steroids may work by suppression of inflammatory mediators such as prostaglandins, bradykinins, and histamines. ${ }^{13}$ It has been shown that inflammation is an important mediator of pain in the interactions between injured disc tissue and the surrounding neural tissue. $^{13}$

Infection after lumbar discectomy has been reported to occur at a rate of $0.2 \%$ with the use of prophylactic antibiotics, which are the standard of care. ${ }^{33}$ It was not explicitly stated whether prophylactic antibiotics were used in the trial by Foulkes and Robinson that reported an infection in the control group. ${ }^{11}$ Lowell et al. reported an increased rate of infection in patients receiving epidural steroids after discectomy, with 3 cases of epidural abscess in the steroid group. ${ }^{24}$ The operating surgeon in this trial reported that there were no cases of infection in the next 439 discectomies he performed after he abandoned the use of epidural steroids. In all other trials that reported complications, no direct correlation was found between epidural steroid usage and complications reported. The only exception to this was in a trial by Jones and Barnett in which 1 case of epidural hematoma was attributed to steroid usage. ${ }^{18}$

Only 2 papers in our review commented on the CSF leakage rate, with no significant impact from the use of steroids. ${ }^{7,17}$ While there are no data on this, in our practice we do not use steroids in cases of intentional or unintentional durotomy.

Based on our analysis, the use of epidural steroids after lumbar discectomy is linked with a higher infection rate but this increased rate does not reach statistical significance. The overall rate of complications after microdiscectomy is low, especially infectious complications, making it difficult to draw conclusions from a single study, but pooling patients from all eligible studies increases the statistical power. In the combined trials there were 20 total complications in the steroid groups (20/742 [2.69\%]) 14 in the control groups $(14 / 1191$ [1.18\%]). In the combined trials there were 7 infections in patients who received epidural steroids $(7 / 742[0.94 \%])$ and 1 infection in the control groups (1/1191 [0.08\%]). The rate of complications does not show a significant difference between the steroid and control groups when comparing total complications ( $\mathrm{p}$ $=0.19)$ or when comparing infection rate alone $(p=0.10)$.

It has been hypothesized that the use of steroids as an adjunct postdiscectomy will decrease pain by prevention of epidural fibrosis and limiting the degree of scar formation. ${ }^{14}$ Häckel et al. published a study that found a statistically significant correlation between the degree of fibrosis and pain, but reported that the application of epidural steroids was not associated with a lower incidence of scar formation or failed back surgery syndrome. ${ }^{14}$ Theoretically, the antiinflammatory effect of epidural steroids could delay healing of the disc space and decrease fibrous tissue formation, hence decreasing the likelihood of reherniation. There were 3 cases of reherniation in the steroid groups $(3 / 742[0.4 \%])$ versus 5 cases in all of the control groups $(5 / 1191[0.42 \%])$, with no significant difference $(p$ $=1.000)$.

There is good evidence that epidural steroid usage decreases short-term pain, but it may not be effective for prevention of long-term pain. Four studies found there to be no significant pain reduction; 9,17,25,28 8 studies reported significant pain reduction, $1,2,8,12,15,29,32$ but none of these studies except 1 reported there to be any difference between placebo and treatment groups for any period longer than 6 weeks. ${ }^{32}$ Five of the 7 studies that commented on neurological impairment found impairment to be significantly reduced in the patient population that received epidural

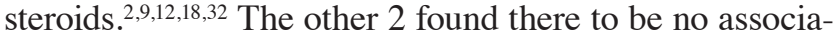
tion. ${ }^{8,29}$ Rasmussen et al. published a study that demonstrated a $24 \%$ reduction in neurological impairment in the steroid group compared with the control group, in addition to a slight reduction in reoperation after a 2-year follow-up. ${ }^{32}$ Debi et al. found no difference in neurological 


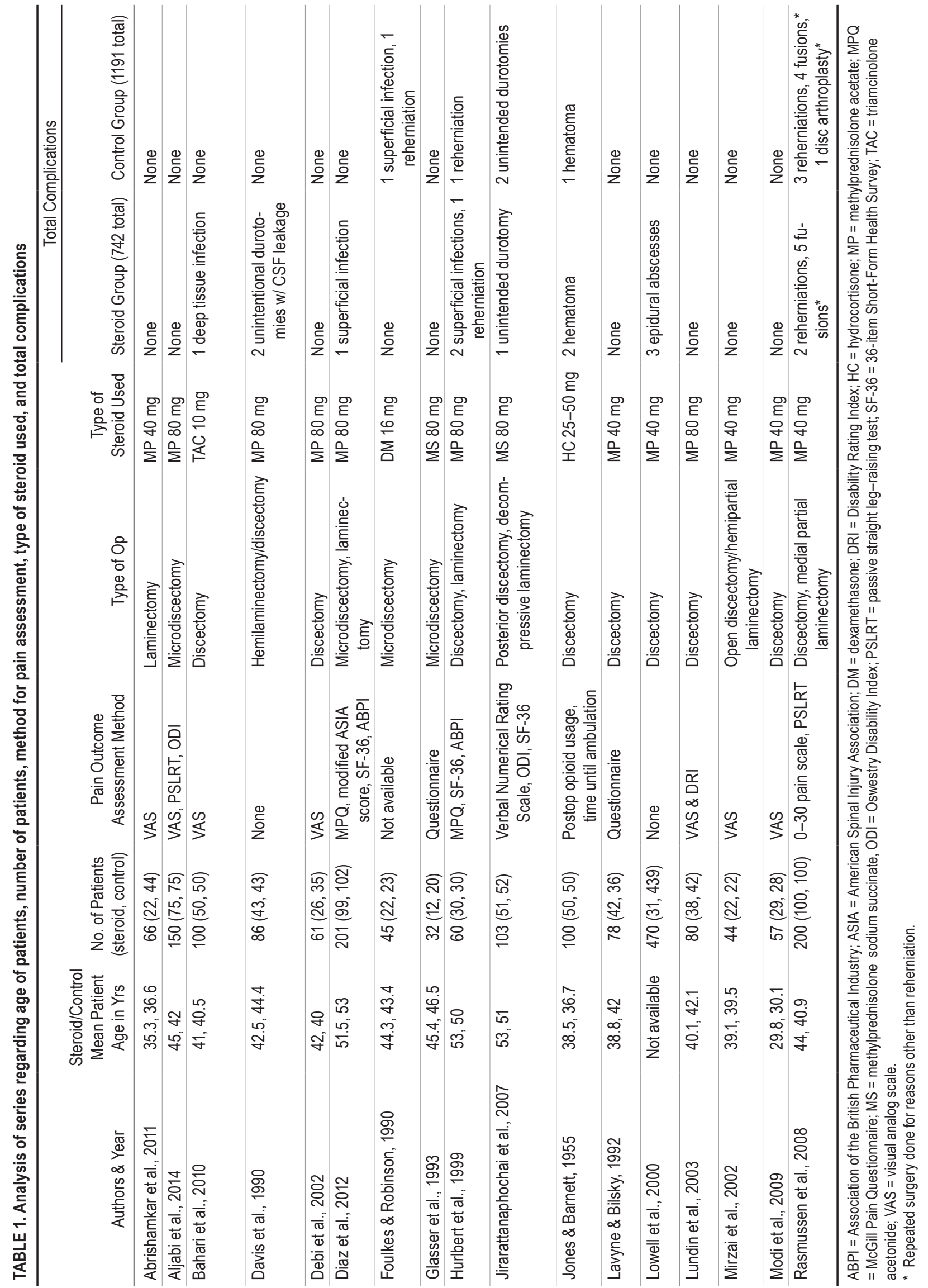




\begin{tabular}{|c|c|c|c|c|c|c|c|c|c|}
\hline Study or Subgroup & \multicolumn{2}{|c|}{ Experimental } & \multicolumn{2}{|c|}{ Control } & Weight & $\begin{array}{c}\text { Risk Ratio } \\
\text { M-H, Random, } 95 \% \mathrm{Cl}\end{array}$ & \multicolumn{3}{|c|}{$\begin{array}{c}\text { Risk Ratio } \\
\text { M-H, Random, } 95 \% \mathrm{CI}\end{array}$} \\
\hline Abrishamkar et al & 0 & 22 & 0 & 44 & & Not estimable & & & \\
\hline Ajabi et al & 0 & 75 & 0 & 75 & & Not estimable & & & \\
\hline Bahari et al & 1 & 50 & 0 & 50 & $7.5 \%$ & $3.00[0.13,71.92]$ & & & \\
\hline Davis et al & 2 & 43 & 0 & 43 & $8.2 \%$ & $5.00[0.25,101.18]$ & & & \\
\hline Debi et al & 0 & 26 & 0 & 35 & & Not estimable & & & \\
\hline Diaz et al & 1 & 99 & 0 & 102 & $7.5 \%$ & $3.09[0.13,74.96]$ & & & \\
\hline Foulkes \& Robinson & 0 & 22 & 2 & 23 & $8.3 \%$ & $0.21[0.01,4.12]$ & & & \\
\hline Glasser et al & 0 & 12 & 0 & 20 & & Not estimable & & & \\
\hline Hurlbert et al & 3 & 30 & 1 & 30 & $12.5 \%$ & $3.00[0.33,27.23]$ & & & \\
\hline Jirarattanaphochai et al & 1 & 51 & 2 & 52 & $11.4 \%$ & $0.51[0.05,5.45]$ & & & \\
\hline Jones \& Barnett & 2 & 50 & 1 & 50 & $11.4 \%$ & $2.00[0.19,21.36]$ & & & \\
\hline Lawne \& Bilsky & 0 & 42 & 0 & 36 & & Not estimable & & & \\
\hline Lowell et al & 3 & 31 & 0 & 439 & $8.5 \%$ & $96.25[5.08,1823.16]$ & & & $\longrightarrow$ \\
\hline Lundin et al & 0 & 38 & 0 & 42 & & Not estimable & & & \\
\hline Mirzai et al & 0 & 22 & 0 & 22 & & Not estimable & & & \\
\hline Modi et al & 0 & 29 & 0 & 28 & & Not estimable & & & \\
\hline Rasmussen et al & 7 & 100 & 8 & 100 & $24.6 \%$ & $0.88[0.33,2.32]$ & & & \\
\hline Total $(95 \% \mathrm{CI})$ & & 742 & & 1191 & $100.0 \%$ & $1.94[0.72,5.26]$ & & & \\
\hline Total events & 20 & & 14 & & & & & & \\
\hline $\begin{array}{l}\text { Heterogeneity. } \mathrm{Tau}^{2}=0 \\
\text { Test for overall effect: } z\end{array}$ & $\begin{array}{l}81 ; \mathrm{Chi}^{2}= \\
=1.30(\mathrm{P}\end{array}$ & $\begin{array}{r}12.82 \\
=0.191\end{array}$ & $d f=8(P$ & $P=0$ & $y ; 1^{2}=3$ & & $\begin{array}{c}0.1 \\
\text { Favors [experimental] }\end{array}$ & Favors [control] & $\overrightarrow{100}$ \\
\hline
\end{tabular}

FIG. 2. Risk ratio with $95 \%$ confidence intervals and forest plot for total complications in studies reporting on epidural steroid usage in lumbar discectomy. $\mathrm{M}-\mathrm{H}=$ Mantel-Haenszel.

impairment between steroid and control groups, but the study was not designed to properly compare the groups. ${ }^{8}$

The reduction in use of opioid analgesics could potentially reduce the overall incidence of oversedation, respiratory depression, dizziness, mental disturbances, constipation, ileus, and other adverse effects associated with narcotics. Ten of the 12 studies that commented on postoperative opioid usage found there to be significantly reduced usage in patients receiving epidural steroids postoperatively. 2,5,7,9,11,12,15,17,18,28 There is good evidence that the use of epidural steroids after lumbar discectomy decreases opioid analgesic use and pain in the short term. The hospital stay after an uncomplicated discectomy is typically less than 24-48 hours. The trial by Davis and Emmons reported a $37 \%$ reduction in postoperative hospital stay in the steroid group. ${ }^{7}$ Fourteen of the trials commented on postoperative hospital stay and 7 found a significant reduction in the steroid group. . $7,11,12,25,29,32$

There are several limitations to this study. Most papers reviewed were not designed to analyze complications; therefore, the details of the patients who experienced complications were sometimes not available. Considering the small number of events, it is possible that with a larger sample size, the infectious complications could be more common in the steroid group, and therefore further studies are necessary. The follow-up time may not have been adequate to effectively assess complication rate in all of the studies. An example of this is the study by Abrishamkar et al. that stated no complications were detected during 14 days of follow-up. ${ }^{1}$ Also, trials may have excluded some patients with complications. For example, Diaz et al. excluded patients with CSF leaks. ${ }^{9}$ While it is difficult to

\begin{tabular}{|c|c|c|c|c|c|c|c|c|}
\hline Study or Subgroup & \multicolumn{2}{|c|}{ Experimental } & \multicolumn{2}{|c|}{ Control } & Weight & $\begin{array}{c}\text { Risk Ratio } \\
\text { M-H, Random, } 95 \% \text { Cl }\end{array}$ & \multicolumn{2}{|c|}{$\begin{array}{c}\text { Risk Ratio } \\
\mathrm{M}-\mathrm{H}, \text { Random, } 95 \% \mathrm{CI}\end{array}$} \\
\hline Abrishamkar et al & 0 & 22 & 0 & 44 & & Not estimable & & \\
\hline Aljabi et al & 0 & 75 & 0 & 75 & & Not estimable & & \\
\hline Bahari et al & 1 & 50 & 0 & 50 & $19.3 \%$ & $3.00[0.13,71.92]$ & & \\
\hline Davis et al & 0 & 43 & 0 & 43 & & Not estimable & & \\
\hline Debi et al & 0 & 26 & 0 & 35 & & Not estimable & & \\
\hline Diaz et al & 1 & 99 & 0 & 102 & $19.3 \%$ & $3.09[0.13,74.96]$ & & \\
\hline Foulkes \& Robinson & 0 & 22 & 1 & 23 & $19.5 \%$ & $0.35[0.01,8.11]$ & & \\
\hline Glasser et al & 0 & 12 & 0 & 20 & & Not estimable & & \\
\hline Hurlbert et al & 2 & 30 & 0 & 30 & $20.7 \%$ & $5.00[0.25,99.95]$ & & \\
\hline Jirarattanaphochai et al & 0 & 51 & 0 & 52 & & Not estimable & & \\
\hline Jones \& Barnett & 0 & 50 & 0 & 50 & & Not estimable & & \\
\hline Lamne \& Bilsky & 0 & 42 & 0 & 36 & & Not estimable & & \\
\hline Lowell et al & 3 & 31 & 0 & 439 & $21.1 \%$ & $96.25[5.08,1823.16]$ & & \\
\hline Lundin et al & 0 & 38 & 0 & 42 & & Not estimable & & \\
\hline Mirzai et al & 0 & 22 & 0 & 22 & & Not estimable & & \\
\hline Modi et al & 0 & 29 & 0 & 28 & & Not estimable & & \\
\hline Rasmussen et al & 0 & 100 & 0 & 100 & & Not estimable & & \\
\hline Total $(95 \% \mathrm{CI})$ & & 742 & & 1191 & $100.0 \%$ & $4.58[0.75,27.95]$ & & \\
\hline Total events & 7 & & 1 & & & & & \\
\hline $\begin{array}{l}\text { Heterogeneity. } \mathrm{Tau}^{2}=1 \\
\text { Test for overall effect: } Z\end{array}$ & $\begin{array}{l}\mathrm{Chi}^{2}= \\
1.65(\mathrm{P}\end{array}$ & $86, d$ & $d f=4(P$ & $=0.14$ & $\% I^{2}=42 \%$ & & $\begin{array}{c}0.1 \\
\text { Favors [experimental] }\end{array}$ & Favors [control] \\
\hline
\end{tabular}

FIG. 3. Risk ratio with $95 \%$ confidence intervals and forest plot for infectious complications in studies reporting on epidural steroid usage in lumbar discectomy. 
TABLE 2. Results of studies examining reduction in neurological impairment, reduction in postoperative hospital stay, pain reduction, and reduction in narcotic use

\begin{tabular}{|c|c|c|c|c|}
\hline Authors \& Year & $\begin{array}{l}\text { Reduction in } \\
\text { Neurological Impairment }\end{array}$ & $\begin{array}{l}\text { Reduction in Postop } \\
\text { Hospital Stay }\end{array}$ & Pain Reduction & $\begin{array}{c}\text { Reduction in Narcotic } \\
\text { Use }\end{array}$ \\
\hline Abrishamkar et al., 2011 & Not available & Not significant & Significant (BP: 12 hrs) & Not available \\
\hline Aljabi et al., 2014 & Significant & Significant & Significant (BP: $1 \mathrm{mo})$ & Significant \\
\hline Bahari et al., 2010 & Not available & Not significant & Significant (BP: 1 day) & Significant \\
\hline Davis \& Emmons, 1990 & Not available & Significant & Not available & Significant \\
\hline Debi et al., 2002 & No association & Not significant & $\begin{array}{l}\text { Significant (BP: } 14 \\
\text { days) }\end{array}$ & Not available \\
\hline Diaz et al., 2012 & Significant & Not significant & Not significant & Significant \\
\hline Foulkes \& Robinson, 1990 & Not available & Significant & Not available & Significant \\
\hline Glasser et al., 1993 & Significant & Significant & $\begin{array}{l}\text { Significant (BP/LP: } 1 \\
\text { day) }\end{array}$ & Significant \\
\hline Hurlbert et al., 1999 & Not available & Not significant & $\begin{array}{l}\text { Significant (BP/LP: } 6 \\
\text { wks) }\end{array}$ & Significant \\
\hline Jirarattanaphochai et al., 2007 & Not available & Not significant & Not significant & Significant \\
\hline Jones \& Barnett, 1955 & Significant & Not available & Not available & Significant \\
\hline Lavyne \& Bilsky, 1992 & Not available & Not significant & Not available & Not significant \\
\hline Lowell et al., 2000 & Not available & Not available & Not available & Not available \\
\hline Lundin et al., 2003 & Not available & Significant & Not significant & Not available \\
\hline Mirzai et al., 2002 & Not available & Not available & Not significant & Significant \\
\hline Modi et al., 2009 & No association & Significant & Significant (BP: 4 wks) & Used NSAIDs \\
\hline Rasmussen et al., 2008 & Significant & Significant & Significant (LP: 1 yr) & Not available \\
\hline
\end{tabular}

$\mathrm{BP}=$ back pain; $\mathrm{LP}=$ leg pain; NSAID = nonsteroidal antiinflammatory.

draw definitive conclusions due to the heterogeneity of the studies, our data certainly raise the possibility that routine use of epidural steroids may not be without complications.

\section{Conclusions}

Based on the analysis of 17 studies assessing the use of epidural steroids after lumbar discectomy, there is some evidence that steroids may not significantly increase the rate of complications. Our data demonstrated a trend toward more infectious complications in the steroid group, but not to a level of statistical significance. There is, however, good evidence that steroids reduce short-term pain and narcotic requirements after surgery. Surgeons who use epidural steroids should be aware of this trend and future studies of epidural steroid efficacy should diligently analyze complications.

\section{References}

1. Abrishamkar S, Rafiei AR, Sabouri M, Moradi S, Tabesh $\mathrm{H}$, Rahmani P, et al: The effect of impregnated autogenous epidural adipose tissue with bupivacaine, methylprednisolone acetate or normal saline on postoperative radicular and low back pain in lumbar disc surgery under spinal anesthesia; A randomized clinical trial study. J Res Med Sci 16:621-626, 2011

2. Aljabi Y, El-Shawarby A, Cawley DT, Aherne T: Effect of epidural methylprednisolone on post-operative pain and length of hospital stay in patients undergoing lumbar microdiscectomy. Surgeon [epub ahead of print], 2014

3. Aminmansour B, Khalili HA, Ahmadi J, Nourian M: Effect of high-dose intravenous dexamethasone on postlumbar discectomy pain. Spine (Phila Pa 1976) 31:2415-2417, 2006

4. Ang ET, Goldfarb G, Kohn S, Galet C, Bex M, Deburge A, et al: [Postoperative analgesia: epidural injection of dexamethasone sodium phosphate.] Ann Fr Anesth Reanim 7:289-293, 1988 (Fr)

5. Bahari S, El-Dahab M, Cleary M, Sparkes J: Efficacy of triamcinolone acetonide and bupivacaine for pain after lumbar discectomy. Eur Spine J 19:1099-1103, 2010

6. Cenic A, Kachur E: Lumbar discectomy: a national survey of neurosurgeons and literature review. Can J Neurol Sci 36:196-200, 2009

7. Davis R, Emmons SE: Benefits of epidural methylprednisolone in a unilateral lumbar discectomy: a matched controlled study. J Spinal Disord 3:299-307, 1990

8. Debi R, Halperin N, Mirovsky Y: Local application of steroids following lumbar discectomy. J Spinal Disord Tech 15:273-276, 2002

9. Diaz RJ, Myles ST, Hurlbert RJ: Evaluation of epidural analgesic paste components in lumbar decompressive surgery: a randomized double-blind controlled trial. Neurosurgery 70:414-424, 2012

10. Ersayli DT, Gurbet A, Bekar A, Uckunkaya N, Bilgin H: Effects of perioperatively administered bupivacaine and bupivacaine-methylprednisolone on pain after lumbar discectomy. Spine (Phila Pa 1976) 31:2221-2226, 2006

11. Foulkes GD, Robinson JS Jr: Intraoperative dexamethasone irrigation in lumbar microdiskectomy. Clin Orthop Relat Res (261):224-228, 1990

12. Glasser RS, Knego RS, Delashaw JB, Fessler RG: The perioperative use of corticosteroids and bupivacaine in the management of lumbar disc disease. J Neurosurg 78:383-387, 1993 
13. Grönblad M, Virri J, Tolonen J, Seitsalo S, Kääpä E, Kankare $\mathrm{J}$, et al: A controlled immunohistochemical study of inflammatory cells in disc herniation tissue. Spine (Phila Pa 1976) 19:2744-2751, 1994

14. Häckel M, Masopust V, Bojar M, Ghaly Y, Horínek D: The epidural steroids in the prevention of epidural fibrosis: MRI and clinical findings. Neuroendocrinol Lett 30:51-55, 2009

15. Hurlbert RJ, Theodore N, Drabier JB, Magwood AM, Sonntag VKH: A prospective randomized double-blind controlled trial to evaluate the efficacy of an analgesic epidural paste following lumbar decompressive surgery. J Neurosurg 90 (2 Suppl): 191-197, 1999

16. Jamjoom BA, Jamjoom AB: Efficacy of intraoperative epidural steroids in lumbar discectomy: a systematic review. BMC Musculoskelet Disord 15:146, 2014

17. Jirarattanaphochai K, Jung S, Thienthong S, Krisanaprakornkit W, Sumananont C: Peridural methylprednisolone and wound infiltration with bupivacaine for postoperative pain control after posterior lumbar spine surgery: a randomized double-blinded placebo-controlled trial. Spine (Phila Pa 1976) 32:609-617, 2007

18. Jones KG, Barnett HC: The use of hydrocortisone in spinal surgery. South Med J 48:617-623, 1955

19. Kararmaz A, Kaya S, Karaman H, Turhanoğlu S, Ozyilmaz A: [Beneficial effects of single dose multimodal epidural analgesia on relief of postoperative microdiscectomy pain.] Agri 16:54-58, 2004 (Turkish)

20. Karst M, Kegel T, Lukas A, Lüdemann W, Hussein S, Piepenbrock S: Effect of celecoxib and dexamethasone on postoperative pain after lumbar disc surgery. Neurosurgery 53:331-337, 2003

21. King JS: Dexamethasone-a helpful adjunct in management after lumbar discectomy. Neurosurgery 14:697-700, 1984

22. Lavyne MH, Bilsky MH: Epidural steroids, postoperative morbidity, and recovery in patients undergoing microsurgical lumbar discectomy. J Neurosurg 77:90-95, 1992

23. Lotfinia I, Khallaghi E, Meshkini A, Shakeri M, Shima M, Safaeian A: Intraoperative use of epidural methylprednisolone or bupivacaine for postsurgical lumbar discectomy pain relief: a randomized, placebo-controlled trial. Ann Saudi Med 27:279-283, 2007

24. Lowell TD, Errico TJ, Eskenazi MS: Use of epidural steroids after discectomy may predispose to infection. Spine (Phila Pa 1976) 25:516-519, 2000

25. Lundin A, Magnuson A, Axelsson K, Kogler H, Samuelsson $\mathrm{L}$ : The effect of perioperative corticosteroids on the outcome of microscopic lumbar disc surgery. Eur Spine J 12:625630, 2003

26. Mack PF, Hass D, Lavyne MH, Snow RB, Lien CA: Postoperative narcotic requirement after microscopic lumbar discectomy is not affected by intraoperative ketorolac or bupivacaine. Spine (Phila Pa 1976) 26:658-661, 2001

27. McNeill TW, Andersson GB, Schell B, Sinkora G, Nelson J,
Lavender SA: Epidural administration of methylprednisolone and morphine for pain after a spinal operation. A randomized, prospective, comparative study. J Bone Joint Surg Am 77:1814-1818, 1995

28. Mirzai H, Tekin I, Alincak H: Perioperative use of corticosteroid and bupivacaine combination in lumbar disc surgery: a randomized controlled trial. Spine (Phila Pa 1976) 27:343346, 2002

29. Modi H, Chung KJ, Yoon HS, Yoo HS, Yoo JH: Local application of low-dose Depo-Medrol is effective in reducing immediate postoperative back pain. Int Orthop 33:737-743, 2009

30. Naylor A, Flowers MW, Bramley JE: The value of dexamethasone in the postoperative treatment of lumbar disc prolapse. Orthop Clin North Am 8:3-8, 1977

31. Ranguis SC, Li D, Webster AC: Perioperative epidural steroids for lumbar spine surgery in degenerative spinal disease. A review. J Neurosurg Spine 13:745-757, 2010

32. Rasmussen S, Krum-Møller DS, Lauridsen LR, Jensen SE, Mandøe H, Gerlif C, et al: Epidural steroid following discectomy for herniated lumbar disc reduces neurological impairment and enhances recovery: a randomized study with twoyear follow-up. Spine (Phila Pa 1976) 33:2028-2033, 2008

33. Schnöring M, Brock M: [Prophylactic antibiotics in lumbar disc surgery: analysis of 1,030 procedures.] Zentralbl Neurochir 64:24-29, 2003 (Ger)

34. Sekar C, Rajasekaran S, Kannan R, Reddy S, Shetty TA, Pithwa YK: Preemptive analgesia for postoperative pain relief in lumbosacral spine surgeries: a randomized controlled trial. Spine J 4:261-264, 2004

35. Weinstein JN, Lurie JD, Olson PR, Bronner KK, Fisher ES: United States' trends and regional variations in lumbar spine surgery: 1992-2003. Spine (Phila Pa 1976) 31:2707-2714, 2006

\section{Disclosure}

Dr. Ahmad is a consultant for DePuy Synthes.

\section{Author Contributions}

Conception and design: Ahmad. Acquisition of data: Akinduro. Analysis and interpretation of data: Akinduro, Haussen. Drafting the article: Akinduro, Miller. Critically revising the article: all authors. Reviewed submitted version of manuscript: all authors. Approved the final version of the manuscript on behalf of all authors: Ahmad. Statistical analysis: Akinduro, Haussen. Study supervision: Ahmad.

\section{Correspondence}

Faiz U. Ahmad, Department of Neurological Surgery, Emory University School of Medicine, 49 Jesse Hill Jr. Dr., Atlanta, GA 30306. email: faiz.ahmad@emory.edu. 